\title{
ANALISIS LANGKAH-LANGKAH PENERAPAN MODEL DISCOVERY LEARNING DALAM PEMBELAJARAN FISIKA
}

\author{
Rosinta Dehong ${ }^{1}$, Melkyanus Bili Umbu Kaleka ${ }^{2}$, Ana Silfiani Rahmawati ${ }^{3}$ \\ 1,2,3 Pendidikan Fisika Universitas Flores, Nusa Tengggara Timur, Indonesia \\ Corresponding author email: rosnidehong@gmail.com
}

Info Artikel

Diterima:

21 September 2020

Disetujui:

3 Desember 2020

Dipublikasikan:

15 Desember 2020

\begin{abstract}
Abstrak:
Penelitian ini bertujuan untuk menganalisis langkah-langkahpenerapan model discovery learning dalam pembelajaran fisika. Jenis penelitian adalah kualitatif dengan jenis studi kasus. Subyek dalam penelitian ini adalah guru fisika dan peserta didik kelas X SMKN 2 Ende yang berjumlah 33 orang peserta didik. Obyek dalam penelitian ini adalah penerapan model discovery learning. Intrumen pengumpulan data menggunakan kuisioner dan dokumentasi. Data dianalisis secara deskriptif. Hasil penelitian menunjukan bahwa penerapan model discovery learning dalam pembelajaran fisika peserta didik kelas $\mathrm{X}$ SMK Negeri 2 Ende sudah sesuai dengan sintaksnya. Sintaks model discovery learning terdiri dari stimulasi, permasalahan, pengumpulan data, pengolahan data, verifikasi, generalisasi.
\end{abstract}

Kata kunci: Model discovery learning, sintaks, penerapan

\begin{abstract}
:
This study aims to analyze the steps of applying the discovery learning model in physics learning. This type of research is qualitative with the type of case study. The subjects in this study were physics teachers and students of class X SMKN 2 Ende, totaling 33 students. The object of this research is the application of the discovery learning model. Data collection instruments using questionnaires and documentation. Data were analyzed descriptively. The results showed that the application of the discovery learning model in physics learning for class $X$ students of SMK Negeri 2 Ende was in accordance with the syntax. The syntax of the discovery learning model consists of stimulation, problems, data collection, data processing, verification, generalization.
\end{abstract}

Key words: Discovery learning model, sintaks, implementation

Copyright $\odot 2020$ Edufisika: Jurnal Pendidikan Fisika

\section{Pendahuluan}

Pendidikan pada dasarnya merupakan suatu proses perubahan tingkah laku dari ketidaktahuan menjadi tahu yang berlangsung secara terus-menerus dalam kehidupan manusia. Pendidikan hendaknya menciptakan sebuah wadah dimana peserta didik bisa secara aktif mempertajam dan menonjolkan semua potensi yang dimilikinya sehingga dapat diterapkannya dalam kehidupan seharihari. Pendidikan yang baik merupakan usaha membantu dan mengarahkan peserta didik untuk menyelesaikan persoalan yang kompleks (Harso, 2020).

Fisika merupakan suatu cabang ilmu pengetahuan alam (IPA) yang mempelajari tentang alam, dimana IPA merupakan suatu ilmu pengetahuan yang mempelajari tentang segala sesuatu yang terjadi di alam baik itu gejala, peristiwa, dan fenomena alam, serta memaparkan segala rahasia dan hukum semesta alam. Sehingga dalam mempelajari fisika, harus melakukan praktikum yang berkaitan dengan materi pelajaran (Oktarinah, 2015). Dalam pembelajaran, fisika bukan semata-mata hanya tugas untuk 
mengumpulkan ilmu pengetahuan yang berupa fakta, konsep dan prinsip tetapi juga merupakan pembelajaran untuk menemukan ilmu pengetahuan.

Pembelajaran fisika diharapkan dapat menjadi suatu wadah untuk belajar tentang diri sendiri dan lingkungan sekitar serta juga dapat mengaplikasikan apa yang dipelajari dalam kehidupan seharihari. Fisika mempunyai tujuan, salah satunya adalah agar peserta didik dapat menguasai konsep dan prinsip fisika untuk mengembangkan pengetahuan, keterampilan, sikap percaya diri sehingga dapat diterapkan dalam kehidupan sehari-hari.

Berdasarkan hasil wawancara salah satu orang guru fisika di SMK Negeri 2 Ende, bahwa model pembelajaran yang diterapkan sebelum belajar di rumah ada dua model pembelajaran yaitu model discovery learning dan model inquiry based learning. Dari kedua model tersebut model yang paling dominan diterapkan dalam kegiatan belajar mengajar adalah model discovery learning. Pembelajaran fisika di SMKN 2 Ende menggunakan model yang diterapkan, peserta didik menguasai materi yang telah diajarkan, dan terlibat aktif dalam proses pembelajaran serta dalam proses pembelajaran peserta didik fokus mendengarkan materi pelajaran

Konsep fisika dapat diwujudkan dalam kehidupan sehari-hari apabila pendidik (guru) mampu memilih model pembelajaran yang tepat dan sesuai dengan tujuan pembelajaran untuk diterapkan. Penggunaan model pembelajaran yang tepat dapat memudahkan peserta didik untuk memahami konsep fisika dan dapat termotivasi dalam mengerjakan tugas sehingga memungkinkan peserta didik dapat mencapai hasil yang lebih baik (Oktarinah, 2015). Model pembelajaran yang digunakan adalah model pembelajaran discovery learning

Discovery learning merupakan suatu model pembelajaran yang berpusat pada peserta didik dimana peserta didik dituntut untuk belajar mandiri dalam mencari, menemukan pengetahuan dan mampu menerapkan pengetahuan yang diperoleh sedangkan tugas guru hanya sebagai fasilitator dalam kegiatan pembelajaran. Discovery learning merupakan suatu model pembelajaran yang berpusat pada peserta didik dimana guru (pendidik) sebagai fasilitator yang menuntun peserta didik dalam menemukan suatu prinsip atau konsep tentang masalah yang terjadi (Suprayanti, 2016). Model penemuan (discovery learning) diharapkan dapat meningkatkan peran peserta didik dalam pembelajaran sehingga dapat meningkatkan hasil belajar serta kualitas pendidikan dalam bidang fisika.

Model pembelajaran merupakan suatu rencana atau pola yang dapat digunakan untuk membentuk kurikulum (perencanaan pembelajaran jangka panjang), merancang bahan-bahan pembelajaran, dan membimbing pembelajaran di kelas (Nurdyansyah, 2016). Model discovery learning (penemuan) merupakan suatu model pembelajaran yang dianggap tepat untuk diterapkan karena dalam proses pembelajaran dapat mengubah kegiatan belajar mengajar yang berorientasi pada guru menjadi berpusat pada peserta didik (Suprayanti, 2016). Dalam pembelajaran discovery learning peserta didik didorong untuk belajar sebagian besar melalui keterlibatan peserta didik itu sendiri dengan konsep dan prinsip dan guru mendorong mereka untuk mempunyai pengalaman dan melakukan percobaan yang memungkinkan menemukan prinsip dan konsep untuk diri mereka sendiri (Ratumanam, 2015).

Dari beberapa pendapat para ahli di atas dapat disimpulkan bahwa model pembelajaran penemuan atau discovery learning merupakan model pembelajaran yang berpusat pada peserta didik, dimana peserta didik diberi kebebasan dan didorong untuk belajar melalui keterlibatan peserta didik itu sendiri secara mandiri untuk memiliki pengalaman dan menemukan prinsip serta konsep.

Terdapat beberapa tujuan model discovery learning (penemuan) seperti berikut ini (Ratumanam, 2015): 1) Memberikan kesempatan kepada peserta didik untuk mengalami proses bagaimana pengetahuan itu diperoleh. 2) Mendorong partisipasi peserta didik secara optimal. Peserta didik akan terlibat aktif baik secara fisik maupun secara kognitif. 3) Mendorong terjadinya proses berpikir tingkat tinggi. Salah satu tujuan model pembelajaran penemuan (discovery learning) adalah sebagai berikut: melatih peserta didik untuk menemukan dan memecahkan masalah tanpa bantuan orang lain dan meminta peserta didik untuk belajar menganalisis dan memanipulasi informasi (Dahar, 2011). Berdasarkan pendapat para ahli di atas diambil kesimpulan tujuan model discovery learning adalah: memberikan kesempatan dan mendorong partisipasi peserta didik untuk mengalami proses pengetahuan diperoleh, untuk terlibat aktif secara fisik maupun kognitif, untuk berpikir tingkat tinggi, melatih peserta didik unntuk menemukan dan memecahkan masalah secara mandiri serta menuntut mereka untuk belajar menganalisis dan mengatur (memanipulasi) informasi. Langkah-langkah (sintak) 
model discovery learning menurut (Ratumanam, 2015) sebagai berikut: 1) Stimulasi/pemberian rangsangan, 2) Pertanyaan/identifikasi masalah, 3) Pengumpulan data, 4) Pengolahan data, 5) Verifikasi dan 6) Generalisasi.

Penelitian yang relevan dengan analisis penerapan model discovery learning dalam pembelajaran fisika adalah penelitian yang berjudul "Penerapan Model Pembelajaran Discovery Learning Terhadap Hasil Belajar Sisiwa Kelas X TAV Pada Standar Kompetensi Melakukan Instalasi Sound System Di SMK Negeri 2 Surabaya". Hasil penelitiannya menunjukan bahwa model pembelajaran discovery learning berpengaruh positif terhadap hasil belajar siswa kelas X TAV (Mubarok, 2014).

Dalam penelitiannya yang berjudul"Pengaruh Model Discovery Learning Terhadap Hasil Belajar Fisika Pada Pokok Bahasan Kalor Di SMP Negeri 2 Pamona Timur", menemukan bahwa terdapat pengaruh model pembelajaran discovery learning terhadap hasil belajar fisika pada pokok bahasan kalor di SMP Negeri 2 Pamona Timur (Sari, 2017). Penelitian tentang "Pengaruh Model Pembelajaran Discovery Learning Terhadap Hasil Belajar Siswa Pada Materi Pokok Suhu Dan Kalor", menemukan bahwa model pembelajaran discovery learning memberi pengaruh signifikan dalam meningkatkan hasil belajar siswa pada materi pokok suhu dan kalor di kelas X semester genap SMA Swasta Budi Satrya Medan T.P2014/2015 (Kadri, 2015).

Penelitian berjudul "Komparasi Model Pembelajaran Discovery Learning dan Problem Solving Ditinjau Dari Hasil Belajar IPA Pada Siswa Kelas 3 SD Di Gugus Diponegoro-Tengaran” dengan hasil penelitian ada perbedaan yang signifikan hasil belajar siswa yang menggunakan model discovery learning dengan hasil belajar siswa yang menggunakan model problem solving pada mata pelajaran IPA tahun 2014/2015 dan pembelajaran menggunakan model discovery learning lebih efektif dari pada pembelajaran menggunakan model problem solving untuk diterapkan pada mata pelajaran IPA tahun 2014/2015 (Mawardi, 2016).

Sesuai latar belakang masalah, maka identifikasi masalah yang diambil peneliti yang merupakan masalah utama dalam penelitian ini adalah 1) model pembelajaran yang diterapkan guru (pendidik) sebelum belajar di rumah yaitu model discovery learning dan inquiry based learning. 2) Peserta didik menguasai materi yang telah diajarkan dan terlibat aktif dalam proses pembelajaran menggunakan model yang diterapkan oleh guru. Berdasarkan identifikasi masalah di atas, maka penelitian ini dibatasi pada analisis penerapan model discovery learning dalam pembelajaran fisika peserta didik SMK Negeri 2 Ende pada materi suhu dan kalor.

Tujuan dalam penelitian ini adalah untuk menganalisis: penerapan model discovery learning dalam pembelajaran fisika peserta didik kelas X SMK Negeri 2 Ende tahun ajaran 2019/2020. Penelitian ini diharapkan dapat bermanfaat, bagi: 1) Bagi sekolah yaitu sebagai salah satu acuan meningkatkan mutu pendidikan dan sebagai acuan pengawasan dan evaluasi pembelajaran fisika pada proses perkembangan setiap peserta didik, sebagai acuan optimalisasi model pembelajaran discovery learning. 2) Bagi guru yaitu sebagai acuan dan evaluasi guru untuk menerapkan model pembelajaran discovery learning. 3) Bagi peserta didik yaitu peserta didik dapat bekerja secara mandiri untuk menemukan prinsip dan konsep fisika dan menerapkannya dalam kehidupan sehari-hari. 4) Bagi peneliti yaiti dapat menambah wawasan keilmuan sebagai bekal menjadi guru fisika yang profesional.

\section{Metode Penelitian}

Jenis Penelitian dan Desain Penelitian

Penelitian ini adalah jenis penelitian studi kasus dengan menggunakan pendekatan deskriptif kualitatif. Penelitian ini digunakan untuk mendapatkan data berupa kata-kata atau kalimat dan analisis menggunakan analisis deskriptif.

Waktu dan Tempat Penelitian

Tempat penelitian ini adalah di SMK Negeri 2 Ende. Alamat: jalan Anggrek, kelurahan Mautapaga, kecamatan Ende Timur, kabupaten Ende, provinsi Nusa Tenggara Timur. Penelitian ini dilaksanakan dari bulan Februari sampai bulan Juli 2020. 
Subjek dan Objek Penelitian

Subyek dalam penelitian ini adalah guru fisika dan peserta didik kelas X Teknik Desain Pemodelan Informasi Bangunan A SMK Negeri 2 Ende yang berjumlah 33 orang peserta didik. Obyek dalam penelitian ini adalah penerapan model discovery learning.

\section{Teknik dan Instrumen Pengumpulan Data}

Teknik pengumpulan data yang digunakan dalam penelitian ini adalah teknik non tes yaitu dalam bentuk wawancara, kuesioner dan dokumentasi. Wawancara merupakan salah satu bentuk teknik pengumpulan data yang dilakukan dengan cara mengadakan tanya jawab dengan sumber data untuk mengumpulkan data yang berkaitan dengan penelitian. dalam penelitian ini teknik wawancara merupakan wawancara awal dengan jumlah pertanyaan 11 butir pertanyaan. Kuesioner atau angket merupakan salah satu teknik pengumpulan data dalam bentuk pertanyaan yang diisi oleh responden sesuai dengan perintah yang tertera. Dalam penelitian ini kuesioner digunakan untuk mengumpulkan informasi atau data yang diperlukan dalam penelitian yaitu penerapan model discovery learning. Dokumentasi dalam penelitian ini digunakan untuk mengumpulkan informasi penting seperti RPP, silabus dan data lain yang menunjang penelitian ini.

Instrumen pengumpulan data yang digunakan dalam penelitian ini adalah lembar wawancara untuk mengetahui model yang diterapkan dalam pembelajaran fisika di sekolah sebelum belajar di rumah, instrumen kuesioner dan dokumentasi untuk menganalisis penerapan model pembelajaran discovery learning dalam pembelajaran fisika.

\section{Keabsahan Data}

Penelitian ini berangkat dari data. Dalam penelitian ini untuk menentukan validitas instrumen peneliti menggunakan professional expert judgement yang artinya instrumen tersebut telah diuji oleh validator ahli. Validator ahli dalam penelitian ini adalah 2 orang dosen pendidikan fisika. Pengujian keabsahan data dalam penelitian ini menggunakan uji kredibilitas data (kepercayaan data) hasil penelitian dengan memfokuskan pada triangulasi. Dalam penelitian ini peneliti menggunakan triangulasi teknik pengumpulan data yaitu wawancara, kuesioner dan dokumentasi.

\section{Teknik Analisis Data}

Teknik analisis data yang digunakan dalam penelitian ini adalah teknik deskriptif. Untuk mengetahui penerapan model discovery learning, teknik analisis data yang digunakan adalah analisis deskriptif, dengan tahapan sebagai berikut: 1) Reduksi data adalah tahap mengurangi atau membuang data yang tidak relevan dengan fokus penelitian. Reduksi data dilakukan dengan memilih hal-hal pokok yang sesuai dengan fokus penelitian agar memberikan gambaran yang lebih tajam. 2) Penyajian data dalam bentuk tabel, grafik, gambar dan sebagainya yang tersusun secara sistematis agar dapat dipahami dan mudah untuk menarik kesimpulan. 3) Verifikasi data/menarik kesimpulan adalah tahap akhir analisis deskriptif yang merupakan hasil dari analisis data (analisis deskriptif).

\section{Hasil Penelitian dan Pembahasan}

Berdasarkan uraian pada bab-bab sebelumnya bahwa teknik pengumpulan data analisis penerapan model discovery learning dalam pembelajaran fisika dalam penelitian ini menggunakan teknik kuesioner dan dokumentasi. Angket diberikan kepada 33 peserta didik kelas X Desain Pemodelan Informasi Bangunan A SMKN 2 Ende. Dokumentasi untuk mengumpulkan informasi seperti RPP dan data lain yang menunjang penelitian ini. Adapun data hasil Kuesioner dan hasil dokumentasi (RPP) adalah berikut ini:

Tabel 1. Hasil Kuesioner Penerapan Model Discovery Learning dalam Pembelajaran Fisika

\begin{tabular}{|c|c|c|}
\hline Variabel & Indikator & Hasil Kuesioner \\
\hline $\begin{array}{l}\text { Penerapan } \\
\text { model } \\
\text { discovery } \\
\text { learning } \\
\text { dalam }\end{array}$ & $\begin{array}{l}\text { Stimulasi/ } \\
\text { rangsangan }\end{array}$ & $\begin{array}{l}\text { Dari } 33 \text { peserta didik sebagai responden } 100 \% \\
\text { peserta didik menjawab guru memberikan } \\
\text { ilustrasi atau gambaran mengenai suatu pokok } \\
\text { bahasan dan guru memberikan pertanyaan yang } \\
\text { menuntun masuk ke dalam permasalahan }\end{array}$ \\
\hline
\end{tabular}




\begin{tabular}{|c|c|c|}
\hline \multirow{6}{*}{$\begin{array}{l}\text { pembelajaran } \\
\text { fisika }\end{array}$} & & \multirow{2}{*}{$\begin{array}{l}\text { pembelajaran } \\
91 \% \text { dari } 33 \text { peserta didik sebagai responden } \\
\text { menjawab guru membimbing dalam } \\
\text { mengidentifikasi masalah }\end{array}$} \\
\hline & $\begin{array}{l}\text { Pertanyaan/ } \\
\text { identifikasi } \\
\text { masalah }\end{array}$ & \\
\hline & $\begin{array}{l}\text { Pengumpulan } \\
\text { data }\end{array}$ & $\begin{array}{l}\text { Peserta didik menjawab guru menugaskan } \\
\text { untuk mengumpulkan informasi dari berbagai } \\
\text { sumber dan guru membimbing dalam } \\
\text { mengumpulkan informasi sebanyak } 97 \% \text { dari } \\
33 \text { peserta didik }\end{array}$ \\
\hline & Pengolahan data & $\begin{array}{l}\text { Dari } 33 \text { jumlah peserta didik (responden) } 100 \% \\
\text { responden menyatakan bahwa guru memantau } \\
\text { dalam mengolah informasi yang telah } \\
\text { dikumpulkan }\end{array}$ \\
\hline & $\begin{array}{l}\text { Verifikasi/ } \\
\text { pembuktian }\end{array}$ & $\begin{array}{l}100 \% \text { Peserta didik menyatakan bahwa guru } \\
\text { menuntun agar memeriksa kembali secara } \\
\text { cermat hasil informasi yang diperoleh }\end{array}$ \\
\hline & $\begin{array}{l}\text { Generalisasi/me } \\
\text { narik } \\
\text { kesimpulan }\end{array}$ & $\begin{array}{l}\text { Peserta didik menyatakan bahwa guru meminta } \\
\text { untuk menarik kesimpulan berdasarkan data } \\
\text { yang diperoleh dan guru memberikan tugas } \\
\text { rumah (PR) sebanyak } 100 \%\end{array}$ \\
\hline
\end{tabular}

Sesuai dengan hasil kuesioner yang diisi responden maka perincian persentase hasil kuesioner, disajikan pada tabel 2 berikut.

Tabel 2. Perincian Persentase Hasil Kuesioner

\begin{tabular}{|c|c|c|c|c|}
\hline \multirow[t]{2}{*}{ Indikator } & \multirow[t]{2}{*}{ Pernyataan } & \multicolumn{2}{|c|}{ Jawaban responden } & \multirow[t]{2}{*}{ Persentase } \\
\hline & & $\mathrm{Ya}$ & Tidak & \\
\hline \multirow[t]{4}{*}{$\begin{array}{l}\text { Stimulasi/ } \\
\text { rangsangan }\end{array}$} & $\begin{array}{l}\text { Pernyataan } 1 \\
\text { (penyataan positif) }\end{array}$ & $\begin{array}{l}33 \times 1 \\
=33\end{array}$ & $0 \times 0=0$ & $\frac{33}{33} \times 100 \%=100 \%$ \\
\hline & $\begin{array}{l}\text { Pernyataan } 2 \\
\text { (penyataan } \\
\text { negatif) }\end{array}$ & $0 \times 0=0$ & $\begin{array}{l}33 \times 1= \\
33\end{array}$ & $\frac{33}{33} \times 100 \%=100 \%$ \\
\hline & $\begin{array}{l}\text { Pernyataan } 3 \\
\text { (penyataan positif) }\end{array}$ & $\begin{array}{l}33 \times 1 \\
=33\end{array}$ & $0 \times 0=0$ & $\frac{33}{33} \times 100 \%=100 \%$ \\
\hline & $\begin{array}{l}\text { Pernyataan } 4 \\
\text { (penyataan } \\
\text { negatif) }\end{array}$ & $0 \times 0=0$ & $\begin{array}{l}33 \times 1 \\
=33\end{array}$ & $\frac{33}{33} \times 100 \%=100 \%$ \\
\hline
\end{tabular}

\begin{tabular}{|c|c|c|c|c|}
\hline \multirow{4}{*}{$\begin{array}{l}\text { Pertanyaan/ } \\
\text { identifikasi } \\
\text { masalah }\end{array}$} & $\begin{array}{l}\text { Pernyataan } 1 \\
\text { (penyataan positif) }\end{array}$ & $\begin{array}{l}33 \times 1 \\
=33\end{array}$ & $0 \times 0=0$ & $\frac{33}{33} \times 100 \%=100 \%$ \\
\hline & $\begin{array}{l}\text { Pernyataan } 2 \\
\text { (penyataan } \\
\text { negatif) }\end{array}$ & $0 \times 0=0$ & $\begin{array}{l}33 \times 1 \\
=33\end{array}$ & $\frac{33}{33} \times 100 \%=100 \%$ \\
\hline & $\begin{array}{l}\text { Pernyataan } 3 \\
\text { (penyataan positif) }\end{array}$ & $\begin{array}{l}27 \times 1= \\
27\end{array}$ & $6 \times 0=0$ & $\begin{aligned} \frac{27}{33} \times 100 \% & =81,8 \% \\
& =82 \%\end{aligned}$ \\
\hline & $\begin{array}{l}\text { Pernyataan } 4 \\
\text { (penyataan } \\
\text { negatif) }\end{array}$ & $6 \times 0=0$ & $\begin{array}{l}27 \times 1= \\
27\end{array}$ & $\begin{aligned} \frac{27}{33} \times 100 \% & =81,8 \% \\
& =82 \%\end{aligned}$ \\
\hline
\end{tabular}

Total persentase $=\frac{100 \%+100 \%+82 \%+82 \%}{4}=91 \%$ 


\begin{tabular}{|c|c|c|c|c|}
\hline \multirow[t]{4}{*}{$\begin{array}{l}\text { Pengumpula } \\
\text { n data }\end{array}$} & $\begin{array}{l}\text { Pernyataan } 1 \\
\text { (penyataan positif) }\end{array}$ & $\begin{array}{l}33 \times 1 \\
=33\end{array}$ & $0 \times 0=0$ & $\frac{33}{33} \times 100 \%=100 \%$ \\
\hline & $\begin{array}{l}\text { Pernyataan } 2 \\
\text { (penyataan } \\
\text { negatif) }\end{array}$ & $0 \times 0=0$ & $\begin{array}{l}33 \times 1 \\
=33\end{array}$ & $\frac{33}{33} \times 100 \%=100 \%$ \\
\hline & $\begin{array}{l}\text { Pernyataan } 3 \\
\text { (penyataan positif) }\end{array}$ & $\begin{array}{l}31 \times 1= \\
31\end{array}$ & $2 \times 0=0$ & $\begin{array}{r}\frac{31}{33} \times 100 \%=93,9 \% \\
=94 \%\end{array}$ \\
\hline & $\begin{array}{l}\text { Pernyataan } 4 \\
\text { (penyataan } \\
\text { negatif) }\end{array}$ & $2 \times 0=0$ & $\begin{array}{l}31 \times 1= \\
31\end{array}$ & $\begin{array}{r}\frac{31}{33} \times 100 \%=93,9 \% \\
=94 \%\end{array}$ \\
\hline
\end{tabular}

\begin{tabular}{|c|c|c|c|c|}
\hline \multirow[t]{4}{*}{$\begin{array}{l}\text { Pengolahan } \\
\text { data }\end{array}$} & $\begin{array}{l}\text { Pernyataan } 1 \\
\text { (penyataan positif) }\end{array}$ & $\begin{array}{l}33 \times 1 \\
=33\end{array}$ & $0 \times 0=0$ & $\frac{33}{33} \times 100 \%=100 \%$ \\
\hline & $\begin{array}{l}\text { Pernyataan } 2 \\
\text { (penyataan } \\
\text { negatif) }\end{array}$ & $0 \times 0=0$ & $\begin{array}{l}33 \times 1= \\
33\end{array}$ & $\frac{33}{33} \times 100 \%=100 \%$ \\
\hline & $\begin{array}{l}\text { Pernyataan } 3 \\
\text { (penyataan positif) }\end{array}$ & $\begin{array}{l}33 \times 1 \\
=33\end{array}$ & $0 \times 0=0$ & $\frac{33}{33} \times 100 \%=100 \%$ \\
\hline & $\begin{array}{l}\text { Pernyataan } 4 \\
\text { (penyataan } \\
\text { negatif) }\end{array}$ & $0 \times 0=0$ & $\begin{array}{l}33 \times 1 \\
=33\end{array}$ & $\frac{33}{33} \times 100 \%=100 \%$ \\
\hline
\end{tabular}

\begin{tabular}{|c|c|c|c|c|}
\hline \multirow[t]{4}{*}{$\begin{array}{l}\text { Verifikasi/ } \\
\text { pembuktian }\end{array}$} & $\begin{array}{l}\text { Pernyataan } 1 \\
\text { (penyataan positif) }\end{array}$ & $\begin{array}{l}33 \times 1 \\
=33\end{array}$ & $0 \times 0=0$ & $\frac{33}{33} \times 100 \%=100 \%$ \\
\hline & $\begin{array}{l}\text { Pernyataan } 2 \\
\text { (penyataan } \\
\text { negatif) }\end{array}$ & $0 \times 0=0$ & $\begin{array}{l}33 \times 1= \\
33\end{array}$ & $\frac{33}{33} \times 100 \%=100 \%$ \\
\hline & $\begin{array}{l}\text { Pernyataan } 3 \\
\text { (penyataan positif) }\end{array}$ & $\begin{array}{l}33 \times 1 \\
=33\end{array}$ & $0 \times 0=0$ & $\frac{33}{33} \times 100 \%=100 \%$ \\
\hline & $\begin{array}{l}\text { Pernyataan } 4 \\
\text { (penyataan } \\
\text { negatif) }\end{array}$ & $0 \times 0=0$ & $\begin{array}{l}33 \times 1 \\
=33\end{array}$ & $\frac{33}{33} \times 100 \%=100 \%$ \\
\hline
\end{tabular}

\begin{tabular}{lllll} 
Total persentase $=\frac{100 \%+100 \%+100 \%+100 \%}{4}=100 \%$ \\
\hline $\begin{array}{l}\text { Generalisasi/ } \\
\text { menarik } \\
\text { kesimpulan }\end{array}$ & $\begin{array}{l}\text { Pernyataan 1 } \\
\text { (penyataan positif) }\end{array}$ & $33 \times 13$ & $0 \times 0=0$ & $\frac{33}{33} \times 100 \%=100 \%$ \\
\cline { 2 - 5 } & $\begin{array}{l}\text { Pernyataan 2 } \\
\text { (penyataan }\end{array}$ & $0 \times 0=0$ & $33 \times 1=$ & $\frac{33}{33} \times 100 \%=100 \%$ \\
& negatif) & 33 & \\
\cline { 2 - 5 } & $\begin{array}{l}\text { Pernyataan 3 } \\
\text { (penyataan positif) }\end{array}$ & $=33 \times 1$ & $0 \times 0=0$ & $\frac{33}{33} \times 100 \%=100 \%$ \\
\cline { 2 - 5 } & $\begin{array}{l}\text { Pernyataan 4 } \\
\text { (penyataan }\end{array}$ & $0 \times 0=0$ & $33 \times 1$ & $\frac{33}{33} \times 100 \%=100 \%$ \\
negatif) & & $=33$ & \\
\hline
\end{tabular}

Total persentase $=\frac{100 \%+100 \%+100 \%+100 \%}{4}=100 \%$

Berdasarkan tabel 2 maka persentase hasil kuesioner dapat dilihat pada gambar 2. berikut. 


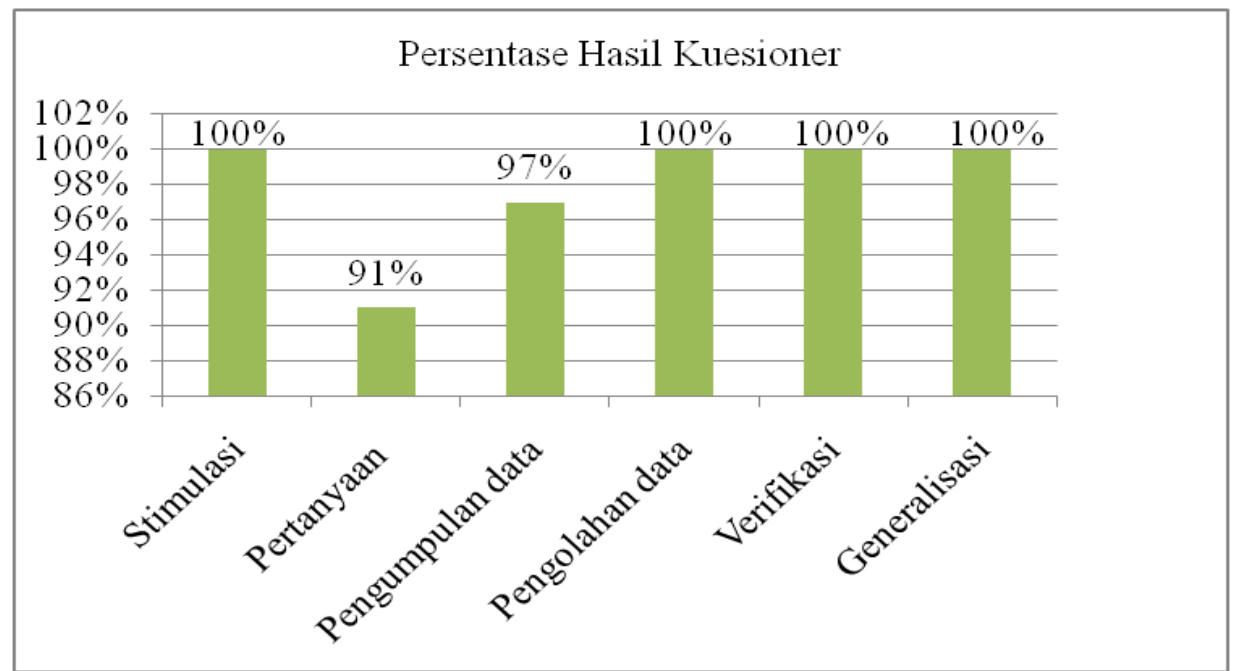

Gambar 2. Persentase Hasil Kuesioner

Rata-rata hasil angket $=\frac{\text { Total persentase setiap indikator hasil kuesioner }}{\text { jumlah } \text { indikator } \text { kuesioner }}$

$$
\begin{aligned}
& =\frac{100 \%+91 \%+97 \%+100 \%+100 \%+100 \%}{6} \\
& =\frac{588 \%}{6} \\
& =98 \%
\end{aligned}
$$

Tabel 3. Interpretasi Kategori Penilaian (Maharani, 2014:65)

\begin{tabular}{cc}
\hline Persentase & Kategori \\
\hline $90 \%-100 \%$ & Sangat tinggi \\
\hline $80 \%-89 \%$ & Tinggi \\
\hline $70 \%-79 \%$ & Cukup tinggi \\
\hline $60 \%-69 \%$ & Sedang \\
\hline $50 \%-59 \%$ & Rendah \\
\hline$<49 \%$ & Sangat rendah \\
\hline
\end{tabular}

Berdasarkan data hasil kuesioner pada table 1 dimana hasil kuesioner yeng diisi responden yang berjumlah 33 peserta didik. Hasil kuesioner penerapan model discovery learning yang terdiri dari enam indikator, keenam indikator kuesioner merupakan sintaks atau langkah-langkah model discovery learning. Setiap indikator terdapat empat pernyataan yeng terdiri dari dua pernyataan positif dan dua pernyataan negatif. Skor untuk pernyataan positif yang menjawab ya mendapat skor 1 (satu) dan yang menjawab tidak mendapat skor 0 (nol) sedangkan untuk pernyataan negatif yang menjawab ya

\begin{tabular}{|c|c|c|}
\hline Variabel & Indikator & Hasil Dokumentasi (RPP) \\
\hline \multirow{2}{*}{$\begin{array}{l}\text { Penerapan } \\
\text { model } \\
\text { discovery } \\
\text { learning } \\
\text { dalam } \\
\text { pembelajaran } \\
\text { fisika }\end{array}$} & $\begin{array}{l}\text { Stimulasi/ } \\
\text { rangsangan }\end{array}$ & $\begin{array}{l}\text { Berdasarkan hasil analisis dokumentasi (RPP) } \text { guru } \\
\text { memberikan gambaran/ilustrasi tentang pentingnya } \\
\text { memahami materi suhu dan kalor dan guru } \\
\text { membagikan LKPD kepada peserta didik }\end{array}$ \\
\hline & $\begin{array}{l}\text { Pertanyaan/ } \\
\text { identifikasi } \\
\text { masalah }\end{array}$ & $\begin{array}{l}\text { Sesuai hasil dokumentasi guru memberikan } \\
\text { kesempatan pada peserta didik untuk mengidentifikasi } \\
\text { sebanyak mungkin pertanyaan yang berkaitan dengan } \\
\text { tugas kelompok yang tertera dalam LKPD } \\
\text { guru membimbing peserta didik dalam }\end{array}$ \\
\hline
\end{tabular}
mendapat skor 0 (nol) dan yang menjawab tidak mendapat skor 1 (satu).

Tabel 4. Hasil Dokumentasi Penerapan Model Discovery Learning dalam Pembelajaran Fisika 


\begin{tabular}{|c|c|}
\hline & $\begin{array}{l}\text { mengidentifikasi masalah tentang suhu dan kalor yang } \\
\text { tertera pada LKPD }\end{array}$ \\
\hline $\begin{array}{l}\text { Pengumpulan } \\
\text { data }\end{array}$ & $\begin{array}{l}\text { Dari hasil dokumentasi (RPP) guru meminta dan } \\
\text { mendorong peserta didik untuk mengumpulkan } \\
\text { informasi tentang materi suhu dan kalor dan guru } \\
\text { membimbing peserta didik dalam mengumpulkan } \\
\text { informasi tentang suhu dan kalor. }\end{array}$ \\
\hline $\begin{array}{l}\text { Pengolahan } \\
\text { data }\end{array}$ & $\begin{array}{l}\text { Peserta didik menganalisis tentang materi } \\
\text { pembelajaran yaitu suhu dan kalor, guru membantu } \\
\text { dan mengawasi peserta didik dalam merencanakan dan } \\
\text { menyiapkan hasil kerja kelompok tentang suhu dan } \\
\text { kalor. }\end{array}$ \\
\hline $\begin{array}{l}\text { Verifikasi/ } \\
\text { pembuktian }\end{array}$ & $\begin{array}{l}\text { Berdasarkan hasil dokumentasi guru menuntun peserta } \\
\text { didik untuk memeriksa kembali secara cermat hasil } \\
\text { kerja kelompok tentang suhu dan kalor. }\end{array}$ \\
\hline $\begin{array}{l}\text { Generalisasi/m } \\
\text { enarik } \\
\text { kesimpulan }\end{array}$ & $\begin{array}{l}\text { Sesuai hasil dokumentasi guru dan peserta didik } \\
\text { menyimpulan hasil pembelajaran tentang suhu dan } \\
\text { kalor. }\end{array}$ \\
\hline
\end{tabular}

Berdasarkan tabel 4, hasil dokumentasi (RPP) bahwa penerapan model discovery learning dalam kegiatan pembelajaran terdiri dari enam langkah-langkah pembelajaran. Langkah-langkah pembelajaran yang diterapkan dalam kegiatan pembelajaran merupakan langkah-langkah atau sintaks model discovery learning.

Berdasarkan hasil kuesioner (angket) yang terdiri dari enam indikator dengan persentase masing-masing setiap indikator secara berturut-turut adalah; 100\%, 91\%, 97\%, 100\%, $100 \%$ dan 100\%. Rata-rata persentase hasil angket (kuesioner) adalah 98\% dimana sesuai tabel interpretasi kategori penilaian maka penerapan model discovery learning berdasarkan hasil angket kategori penilaian sangat tinggi. Kuesioner tersebut diisi oleh responden yang berjumlah 33 orang peserta didik kelas X Desain Pemodelan Informasi Bangunan A SMKN 2 Ende.

Berdasarkan hasil kuesioner dan hasil dokumentasi (RPP) Penerapan model discovery learning dalam pembelajaran fisika diterapkan sesuai dengan sintaks model discovery learning seperti berikut: Stimulus/rangsangan penerapan model discovery learning dalam pembelajaran fisika untuk indikator stimulus/rangsangan adalah $100 \%$ dimana guru memberikan ilustrasi atau gambaran mengenai suatu pokok bahasan dan guru memberikan pertanyaan yang menuntun peserta didik masuk ke dalam permasalahan pembelajaran.

Penerapan model discovery learning pada indikator pertanyaan atau identifikasi masalah berdasarkan hasil kuesioner adalah $91 \%$ yang merupakan persentase terendah dari enam indikator kuesioner yang merupakan sintaks model discovery learning dengan kegiatan peserta didik mengidentifikasi masalah dan guru membimbing peserta didik dalam mengidentifikasi masalah.

Penerapan model discovery learning dalam pembelajaran fisika pada indikator pengumpulan data yaitu peserta didik mengumpulkan informasi dari berbagai sumber dan guru membimbing dalam mengumpulkan informasi dengan persentase penerapan berdasarkan hasil kuesioner $97 \%$.

Pengolahan data merupakan salah satu sintaks model discovery learning dan indikator kuesioner, pada indikator ini sesuai hasil kuesioner persentase indikator $100 \%$. Penerapan model discovery learning pada indikator pengolahan data adalah peserta didik mengolah informasi yang telah dikumpulkan adalah guru memantau peserta didik dalam mengolah informasi yang telah dikumpulkan.

Verifikasi/pembuktian; penerapan model discovery learning pada indikator verifikasi/pembuktian adalah guru (pendidik) menuntun agar peserta didik memeriksa kembali secara cermat hasil informasi yang diperoleh. Persentase hasil kuesioner pada indikator verifikasi atau pembuktian adalah $100 \%$.

Generalisasi/menarik kesimpulan penerapan model discovery learning pada indikator generalisasi/menarik kesimpulan yaitu peserta didik dan guru menarik kesimpulan dari informasi yang diperoleh dengan persentase hasil kuesioner (angket) adalah $100 \%$. 


\section{Simpulan}

Berdasarkan hasil penelitian maka dapat disimpulkan bahwa penerapan model discovery learning dalam pembelajaran fisika peserta didik kelas X SMK Negeri 2 Ende diterapkan dengan kategori penilaian sangat tinggi dan dilaksanakan sesuai dengan sintaks atau langkah-langkah model pembelajaran discovery learning. Sintaks model discovery learning terdiri dari stimulasi, permasalahan, pengumpulan data, pengolahan data, verifikasi, generalisasi.

\section{Referensi}

Dahar, R. (2011). Teori-Teori Belajar \& Pembelajaran. Jakarta: Penerbit Erlangga.

Harso, A., Karolus, K. K., \& Yasinta, E. I. (2020). Pengaruh Model Pembelajaran Generatif Terhadap Kreativitas SAINS Siswa Kelas VIII SMP Swasta Ilebura Lewotobi. Jurnal Pendidikan Fisika,4(1), 38-45

Ibrahim, A., Asrul, H. A., Madi., \& Muhammad, A. A. (2018). Metodologi Penelitian. Cetakan 1. Makassar: Gunadarma Ilmu.

Kadri, M., \& Meika, R. (2015). Pengaruh Model Pembelajaran Discovery Learning Terhadap Hasil Belajar Siswa Pada Materi Pokok Suhu dan Kalor. Jurnal Ikatan Alumni Fisika Universitas Negeri Medan,1 (1), 29-33.

Maharani, F. (2014). Pengaruh Promosi Dan Minat Baca Terhadap Kunjungan Pemustaka Ke Perpustakaan SD SALMAN AL FARISI Bandung. Tesis, dipublikasikan. Universitas Pendidikan Indonesia.

Mawardi., \& Mariati. (2016). Komparasi Model Pembelajaran Discovery Learning Dan Problem Solving Ditinjau Dari Hasil Belajar IPA Pada Siswa Kelas 3 SD Di Gugus Diponegoro-Tengaran. Scolaria,6 (1), 127-142.

Mubarok, C., \& Edy, S. (2014). Penerapan Model Pembelajaran Discovery Learning Terhadap Hasil Belajar Siswa Kelas X TAV Pada Standar Kompetensi Melakukan Instalasi Sound System Di SMK Negeri 2 Surabaya. Jurnal Pendidikan Teknik Elektro,3 (1), 215-221.

Nurdyansyah., \& Eni, F. F. (2016). Inovasi Model Pembelajaran. Cetakan Pertama. Surabaya: Nizamia Learning Center Sidoarjo.

Oktarinah., Ketang, W., \& Zulherman. (2015). Pengembangan Bahan Ajar Berbasis Model Pembelajaran Proyek Materi Alat-Alat Optik Untuk Kelas X SMA. Jurnal Inovasi Pembelajaran Fisika,1-7

Ratumanam. (2015). Inovasi Pembelajaran. Yogyakarta: Ombak.

Sari, E. R., Marungkil, P., \& Sahrul, S. (2017). Pengaruh Model Pembelajaran Discovery Learning Terhadap Hasil Belajar Fisika Pada Pokok Bahasan Kalor Di SMP Negeri 2 Pamona Timur. Jurnal Inovasi dan Pembelajaran Fisika,119-126

Suprayanti, I., Syahrial., \& Satutik, R. (2016). Penerapan Model Pembelajaran Discovery Learning Berbantuan Alat Peraga Sederhana Untuk Meningkatkan Aktivitas dan Hasil Belajar Siswa Kelas VII SMPN 5 Jonggat Tahun Pelajaran 2015/2016. Jurnal Pandidikan Fisika Dan Teknologi,2 (1), 20-35 